\title{
Administração de acetato de melengestrol após inseminação artificial em tempo fixo em vacas nelore lactantes
}

\author{
Administration of melengestrol acetate after fixed time artificial insemination in \\ lactating Nelore cows
}

\author{
RODRIGUES, Moraima Castro ${ }^{1 *}$; LEÃO, Karen Martins ${ }^{1}$; SILVA, Natália do \\ Carmo $^{1}$; SILVA, Rossane Pereira da ${ }^{1}$; VIU, Marco Antônio de Oliveira ${ }^{2}$; CARDOSO, \\ Lucas Morais $^{3}$
}

${ }^{1}$ Instituto Federal de Educação, Ciência e Tecnologia, Rio Verde, Goiás, Brasil.
${ }^{2}$ Universidade Federal de Goiás, Departamento de Zootecnia, Jatá, Goiás, Brasil.
${ }^{3}$ Médico Veterinário, Autônomo, Rio Verde, Goiás, Brasil.
*Endereço para correspondência: moraima_rv@hotmail.com

RESUMO

Objetivou-se com este estudo avaliar o efeito do fornecimento de Acetato de Melengestrol $\left(\mathrm{MGA}^{\circledR}\right.$ Premix) após IATF (inseminação artificial em tempo fixo), sobre a taxa de concepção em vacas paridas da raça Nelore. Experimento I, avaliou-se o efeito do fornecimento de $2,28 \mathrm{~g}$ de MGA/ vaca/ dia, do dia 13 (D13) ao dia 18 (D18) após a IATF. As vacas foram divididas em dois grupos, sendo o Grupo I ( $\mathrm{n}=83$, controle) que foi realizado apenas IATF e Grupo II ( $\mathrm{n}=104$, tratado) que foi fornecido o MGA após a IATF. Experimento II, avaliou-se o efeito do fornecimento de 2,28g de MGA/ vaca/ dia, do dia cinco (D5) ao dia 10 (D10) após a IATF. As vacas foram divididas em dois grupos, sendo o Grupo I $(\mathrm{n}=94$, controle) que foi realizado apenas IATF e Grupo II ( $\mathrm{n}=100$, tratado) que foi fornecido o MGA após a IATF. O diagnóstico de gestação foi realizado 45 dias após a IATF em ambos os experimentos. As taxas de concepção foram comparadas pelo teste de Qui-quadrado. No Experimento I, as taxas de concepção foram de $42,16 \%$ para o grupo controle e $50,0 \%$ para o grupo tratado. No Experimento II, a taxa de concepção do grupo controle $(47,87 \%)$ foi significativamente maior do que o grupo tratado $(28,0 \%)$. Conclui-se que o fornecimento de MGA ${ }^{\circledR}$ Premix, administrado do D13 ao D18 após a IATF não afetou a taxa concepção. Entretanto, quando fornecido do D5 ao D10, reduziu a taxa de concepção em vacas Nelore paridas.

Palavras-chave: ambiente uterino, progestágeno, sincronização de ovulação, taxa de concepção

\section{SUMMARY}

The objective of the present study was to assess the effect of administration of Melengestrol Acetate $\left(\mathrm{MGA}^{\circledR}\right.$ Premix) after FTAI, on the conception rate in lactating Nelore breed cows. Experiment I, assessed the effect of administration of $2.28 \mathrm{~g} \mathrm{MGA} / \mathrm{cow} /$ day, from day 13 (D13) until day 18 (D18) after FTAI. The cow were divided into two groups, Group I $(n=83$, control) that cows were submitted just to FTAI and Group II ( $\mathrm{n}=104$, treated) that cows received MGA after FTAI. Experiment II, assessed the effect of administration of $2.28 \mathrm{~g}$ MGA/cow/day, from day 5 (D5) until day 10 (D10) after FTAI. The cow were divided into two groups, Group I ( $\mathrm{n}=94$, control) that cows were submitted just to FTAI and Group II $(\mathrm{n}=100$, treated) that cows received MGA after FTAI. Gestation was diagnosed in both experiments 45 days after FTAI. The conception rates were analyzed by Qui-Square test. In experiment I, The conception rates were $42,16 \%$ for control group and 50,0\% for treated group $(\mathrm{p}>0,05)$. In Experiment II, the conception rate of control group $(47,87 \%)$ was higher than treated group $(28,0 \%)$. It was conclude that administration of MGA ${ }^{\circledR}$ Premix from D13 until D18 after FTAI didn't affect the conception rate. However, when administered from D5 until D10, reduced the conception rate in lactating Nelore breed cows.

Keywords: conception rate, ovulation synchronization, progestogen, uterine environment 


\section{INTRODUÇÃO}

Após a fertilização o concepto deve sinalizar a própria presença no organismo materno com o objetivo de evitar a regressão do corpo lúteo (CL) e consequentemente manter a secreção de progesterona $\left(\mathrm{P}_{4}\right)$, para isso o concepto libera proteínas denominadas interferon-tau bovino (HAFEZ \& HAFEZ, 2004).

Caso haja fertilização o embrião produz interferon- $\tau$ (IFN- $\tau$ ) para que ocorra $o$ reconhecimento materno da gestação e mantença do CL. A produção desta substância se inicia entre o $15^{\circ}$ e o $17^{\circ}$ dia de gestação, e se mantém elevada até o $22^{\circ}$ dia da gestação, promovendo a mantença do CL (PALHANO, 2008).

Um embrião bem desenvolvido, secreta elevadas quantidades de interferon-tau (IFN- $\tau$ ) que por sua vez depende da secreção de $\mathrm{P}_{4}$, levando ao sucesso da própria sinalização e consequentemente do reconhecimento materno (MANN \& LAMMING, 2001).

$\mathrm{A} \mathrm{P}_{4}$ é essencial para a harmonia do ambiente uterino, auxiliando o útero a proporcionar maior quantidade de nutrientes para o concepto que são importantes para que o concepto desenvolva. A principal ação da $\mathrm{P}_{4}$ é a inativação da luteólise através da redução da sensibilidade dos receptores de ocitocina (HAFEZ \& HAFEZ, 2004).

A baixa exposição de $\mathrm{P}_{4}$ prejudica $\mathrm{o}$ desenvolvimento embrionário após a concepção, reduzindo a liberação de IFN$\tau$, como consequência promove a transcrição de receptores de ocitocina e a liberação de prostaglandina F2 $\alpha$ (PGF2 $\alpha$ ), que leva a inibição do reconhecimento materno (MANN \& LAMMING, 2001).

$\mathrm{A}_{4}$ gera mudanças na expressão de genes do endométrio e na condução de alterações na composição de células embrionárias, para sobrevivência e desenvolvimento do embrião (BAZER et al., 2008).

Estudos têm demonstrado a necessidade de elevar as concentrações plasmáticas de $\mathrm{P}_{4}$, ou mantê-las na normalidade para melhorar a sinalização materno-fetal e consequentemente o reconhecimento da gestação.

$\mathrm{O}$ acetato de melengestrol $\left(\mathrm{MGA}^{\circledR}\right.$ Premix) é um esteroide progestacional sintético de administração oral, indicado para auxiliar as fêmeas bovinas a manterem a gestação (SÁ FILHO et al., 2007).

Pelo exposto, objetivou-se com este trabalho avaliar o efeito do fornecimento de acetato de melengestrol via oral, após a inseminação artificial em tempo fixo, sobre a taxa de concepção em vacas lactantes da raça Nelore.

\section{MATERIAL E MÉTODOS}

Este projeto foi aprovado pelo Comitê de Ética do Instituto Federal de Educação, Ciência e Tecnologia Goiano e protocolado sob o número 029/2012.

Para avaliar o efeito do fornecimento de acetato de melengestrol $\left(\mathrm{MGA}^{\circledR}\right.$ Premix, Pfizer, 3,5Kg. Huvepharma Inc., St. Louis, Missouri, EUA) do dia 13 (D13) ao dia 18 (D18) após a inseminação artificial em tempo fixo (IATF), foi desenvolvido o Experimento I, realizado em uma propriedade localizada no município de Santo Antônio da Barra, Goiás, Brasil, durante o período de fevereiro de 2013 a abril de 2013. Os animais experimentais foram mantidos em piquetes de capim Brachiaria brizantha cv. Marandu, abastecidos por bebedouros para fornecimento de água ad libitum e cochos cobertos para fornecimento de sal mineral, com dimensionamento de 15 centímetros de 
altura, 30 centímetros de largura e três metros de comprimento.

Foram selecionadas 187 vacas lactantes pluríparas da raça Nelore, com escore decondição corporal médio de 03 (escala de 1 a 5 , sendo 1 muito magra e 5 muito gorda, segundo Ferguson et al. (1994) e com 65 a 90 dias pós parto.

Para o controle do desenvolvimento folicular e sincronização da ovulação as vacas receberam no dia zero (D0) o dispositivo intravaginal contendo 0,75 gramas de progesterona (Prociclar ${ }^{\circledR}$, Hertap Calier, Juatuba, Minas Gerais, Brasil) e 2,0mg de benzoato de estradiol (Gonadiol $^{\circledR}$, Coopers, Luis Guillón, Buenos Aires). Após oito dias $\mathrm{D}(08)$ o dispositivo de progesterona foi retirado e aplicado 0,15 mg de D-Cloprostenol (Croniben $^{\circledR}$, Biogénesis Bago, Mercês, Curitiba, Brasil) e 300 UI de Gonadotrofina Coriônica Equina (Sincro $\mathrm{eCG}^{\circledR}$, Ouro Fino, Uberaba, Minas Gerais, Brasil). No dia nove (D09) foi aplicado 1,0mg de benzoato de estradiol (Gonadiol $^{\circledR}$, Coopers, Luis Guillón, Buenos Aires) e no dia 10 (D10) foi realizada a inseminação artificial em tempo fixo. Os procedimentos de aplicação dos hormônios foram realizados às oito horas e a IATF foi realizada às 14 horas. Para realização dos manejos os animais foram mantidos em tronco de contenção. As vacas dos grupos controle e tratado foram sincronizadas e inseminadas no mesmo dia, com sêmen oriundos de um único touro de raça Aberdeen Angus.

Os animais foram divididos em dois grupos experimentais, sendo que no grupo I (Grupo Controle; $n=83$ ) os animais receberam suplementação mineral sem adição de acetato de melengestrol, conforme suas exigências e no grupo II (GrupoTratado; $n=104$ ) os animais receberam suplementação mineral, com adição de 2,28g de $\mathrm{MGA}^{\circledR}$ Premix/vaca/dia do décimo terceiro dia
(D13) ao décimo oitavo dia (D18) após a IATF.

Para controle do consumo do $\mathrm{MGA}^{\circledR}$ Premix, das vacas do grupo tratado, às oito horas do D13, foi misturado em quatro $\mathrm{kg}$ de sal mineral, 2,28g de $\mathrm{MGA}^{\circledR}$ Premix por animal, quantidades indicadas pelo fabricante. Ao meio dia o cocho foi observado, se não houvesse mais suplemento mineral, adicionado de MGA $^{\circledR}$ Premix, o cocho era reabastecido, com sal mineral puro, se ainda tivesse sal adicionado de produto, o mesmo permanecia até ser completamente consumido e logo após era fornecido sal mineral puro. No dia seguinte às oito horas, se houvesse sobras de suplemento mineral puro no cocho estas eram retiradas antes de um novo fornecimento de suplemento mineral adicionado de $\mathrm{MGA}^{\circledR}$ Premix. Tal procedimento seguiu até o D18.

Para avaliar o efeito do fornecimento de acetato de melengestrol $\left(\mathrm{MGA}^{\circledR}\right.$ Premix, Pfizer, 3,5Kg. Huvepharma Inc., St. Louis, Missouri, EUA) do quinto (D05) ao décimo dia (D10a) após a IATF, foi desenvolvido o Experimento II, realizado em uma propriedade localizada no município de Paraúna, Goiás, Brasil, durante o período de março de 2013 a maio de 2013. Os animais experimentais foram mantidos em piquetes de capim Brachiária brizantha cv. Marandu, abastecidos por bebedouros de água $a d$ libitum e cochos cobertos para fornecimento de sal mineral com dimensionamento de 15 centímetros de altura, 30 centímetros de largura e três metros de comprimento.

Foram selecionadas 194 vacas pluríparas lactantes da raça Nelore, com escore de condição corporal médio de 03 (escala de 1 a 5 , sendo 1 muito magra e 5 muito gorda, segundo Ferguson et al. (1994) e com 50 a 75 dias pós parto. 
No dia zero (D0), as lactantes receberam o dispositivo intravaginal contendo $1 \mathrm{~g}$ de progesterona $\left(\mathrm{DIB}^{\circledR}\right.$, MSD Saúde Animal, Cotia, São Paulo, Brasil) e 2,0mg de benzoato de estradiol (Gonadiol $^{\circledR}$, Coopers, Luis Guillón, Buenos Aires). Após sete dias (D07) foi aplicado $0,15 \mathrm{mg}$ de D-Cloprostenol (Croniben ${ }^{\circledR}$,Biogénesis Bago, Mercês, Curitiba, Brasil). No dia nove (D09) o dispositivo de progesterona foi retirado e aplicado300 UI de Gonadotrofina Coriônica Equina (Sincro eCG ${ }^{\circledR}$, Ouro Fino, Uberaba, Minas Gerais, Brasil) e $0,6 \mathrm{mg}$ de cipionato de estradiol $\left(\mathrm{ECP}^{\circledR}\right.$, Pfizer, Pharmacia and Upjohn Company, NY, USA). Decorridas 48 horas (D11) foram realizadas as inseminações artificiais em tempo fixo. Todos os procedimentos hormonais e as IATFs foram realizados às oito horas. Para realização dos manejos os animais foram mantidos em tronco de contenção. As vacas dos grupos controle e tratado foram sincronizadas e inseminadas no mesmo dia, com sêmen oriundo de um único touro de raça Aberdeen Angus.

Os animais foram divididos em dois grupos experimentais, sendo que no grupo I (Grupo Controle; n=94) os animais receberam suplementação mineral sem adição de acetato de melengestrol, conforme suas exigências e no grupo II (GrupoTratado; $n=100$ ) os animais receberam suplementação mineral, porém com adição de $2,28 \mathrm{~g}$ de acetato de melengestrol/vaca/dia a partir do quinto (D05) ao décimo dia (D10a) após a IATF.

O controle do consumo de $\mathrm{MGA}^{\circledR}$ Premix foi realizado conforme descrito no Experimento I.

O diagnóstico de gestação de ambos os Experimentos foi realizado aos 45 dias após a IATF por meio de exame de ultrassonografia utilizando o equipamento Ultrasson Veterinária KX 2600. Foi considerada prenha a fêmea que apresentou vesícula embrionária com líquido, não ecogênico e presença de um embrião com batimentos cardíacos (NEVES et al., 2008).

Em ambos os experimentos o delineamento foi inteiramente ao acaso. A frequência de vacas gestantes ou não, foi submetida ao teste do Qui Quadrado $\left(\chi^{2}\right)$, por meio do procedimento FREQ (STATISTICAL ANALYSIS SYSTEM, 2000).

\section{RESULTADOS E DISCUSSÃO}

A taxa de concepção aos 45 dias após a IATF do experimento I (Tabela 1), no qual o fornecimento de progesterona foi do $13^{\circ}$ ao $18^{\circ}$ dia após a IATF, foi de $42,16 \%$ para o grupo controle e de $50,00 \%$ para o grupo tratado com progesterona, não diferindo entre si $(\mathrm{P}>0,05)$.

Tabela 1. Taxa de concepção de vacas Nelore lactantes, aos 45 dias após a inseminação artificial em tempo fixo (IATF) nos grupos controle e tratado com progesterona fornecida do $13^{\circ}$ ao $18^{\circ}$ dia após a IATF

\begin{tabular}{llc}
\hline Grupo & $\mathrm{N}$ & Taxa de concepção aos 45 dias \\
\hline Grupo Controle & 83 & $42,16 \% \mathrm{a}$ \\
Grupo Progesterona & 104 & $50,00 \% \mathrm{a}$ \\
\hline
\end{tabular}

Letras diferentes na mesma coluna diferem entre si $(\mathrm{P}<0,05)$. 
A taxa de concepção aos 45 dias após a IATF do experimento II (Tabela 2), em que o fornecimento de progesterona foi do $5^{\circ}$ ao $10^{\circ}$ dia após a IATF, foi de $47,87 \%$ para o grupo controle e de $28,00 \%$ para o grupo tratado com progesterona, diferindo entre si $(\mathrm{P}<0,05)$.

Forde et al. (2011) observaram que a baixa concentração de $\mathrm{P}_{4}$, condições consideradas sub-ótimas, alterou mudanças na expressão gênica do endométrio bovino e a suplementação com $\mathrm{P}_{4}$ exógena também levou a grandes mudanças na transcrição dos genes do endométrio bovino, sendo que, mudança gerada pela baixa $\mathrm{P}_{4}$, foi associada à redução da habilidade do útero de suportar o alongamento do concepto.

Tabela 2. Taxa de concepção de vacas Nelore lactantes, aos 45 dias após a inseminação artificial em tempo fixo (IATF) nos grupos controle e tratado com progesterona fornecida do $5^{\circ}$ ao $10^{\circ}$ dia após a IATF

\begin{tabular}{llc}
\hline Grupo & $\mathrm{N}$ & Taxa de concepção aos 45 dias \\
\hline Grupo Controle & 94 & $47,87 \% \mathrm{a}$ \\
Grupo Progesterona & 100 & $28,00 \% \mathrm{~b}$ \\
\hline
\end{tabular}

Letras diferentes na mesma coluna diferem entre si $(\mathrm{P}<0,05)$.

Já foi demonstrado que em novilhas, a maior expressão de genes endometriais, reguladores de $\mathrm{P}_{4}$, coincidiu com os dias em que a concentração de $\mathrm{P}_{4}$ foi maior e durante maior período de tempo, levando os autores a concluírem que a suplementação com $\mathrm{P}_{4}$ alterou a duração da expressão de genes que contribuem para a composição do leite uterino, que consequentemente contribui para $\mathrm{o}$ desenvolvimento do concepto (FORDE et al., 2009).

Da mesma forma, Carter et al. (2010) observaram que, a elevada concentração de $\mathrm{P}_{4}$ não influenciou no desenvolvimento dos embriões no estágio de blastocisto. Porém, foram encontrados 194 genes, que se expressam de forma diferente em novilhas com concentração de $\mathrm{P}_{4}$ normal e elevada. Embora a concentração de $\mathrm{P}_{4}$ elevada não tenha influenciado o embrião no estágio de blastocisto, a $\mathrm{P}_{4}$ mudou a expressão dos genes durante o estágio de clivagem, que são manifestados depois, com avanço no alongamento após a eclosão.
Semelhante ao que foi observado neste estudo quando as vacas foram suplementadas com MGA ${ }^{\circledR}$ Premix do $5^{\circ}$ ao $10^{\circ}$ dia após a IATF, ShamsEsfandabadi \& Shirazi (2007), também observaram uma redução na taxa de concepção ao fornecerem $\mathrm{P}_{4}$ exógena para vacas logo após a IA $(30,88 \%)$ quando comparada com o grupo controle $(35 \%)$, que não recebeu $\mathrm{P}_{4}$ após a IA.

Entretanto, Larson et al. (2007) que implantaram dispositivos intravaginais de $\mathrm{P}_{4} \mathrm{em}$ vacas de leite entre os dias 3,5 e 10 após a IA, observaram que o grupo controle obteve a taxa de concepção de $35 \%$ e o grupo tratado a taxa de concepção de $48 \%$.

A variação dos resultados obtidos com a suplementação com $\mathrm{P}_{4}$ pós IATF, podem ser justificadas pelo fato que alguns animais apresentem baixos níveis séricos de progesterona, de forma que a suplementação destes animais resulte em efeitos benéficos, elevando a taxa de prenhez e em animais que 
possuem $\mathrm{P}_{4}$ em níveis adequados a suplementação não demonstrou efeito. Mann et al. (2006), implantaram o dispositivo intravaginal de $\mathrm{P}_{4}$ em um grupo de vacas de leite dos cinco aos nove dias após a IA e em outro grupo dos 12 aos 16 dias após a IA. Os pesquisadores, após abaterem os animais e recuperarem os embriões, observaram que a suplementação precoce promoveu o aumento de quatro vezes no alongamento do concepto e elevou seis vezes a concentração de IFN- $\tau$ quando comparado com o grupo controle, enquanto o grupo suplementado tardio não diferiu do grupo controle. Porém, os resultados obtidos neste experimento, mostraram uma redução na taxa de concepção quando a progesterona foi fornecida precocemente, em vacas nelore lactantes.

Também diferindo dos resultados encontrados, Mann \& Lamming (1999) verificaram um aumento na taxa de concepção quando se eleva a $\mathrm{P}_{4}$ na primeira semana após a inseminação, não sendo observado efeito quando a suplementação é realizada na segunda ou terceira semana após a inseminação.

Carter et al. (2008), realizaram estudo em que dividiram um lote de vacas em quatro grupos que foram designados para serem abatidos aos cinco, sete, treze e dezesseis dias do ciclo estral, metade dos animais de cada grupo receberam o dispositivo intravaginal de $\mathrm{P}_{4}$ a partir do dia três do ciclo estral, os dispositivos foram mantidos no aparelho reprodutivo das vacas até os dias de abate e após o abate os embriões foram recuperados. Os pesquisadores observaram que a elevação da $\mathrm{P}_{4}$ a partir do dia três do ciclo estral, estimulou o alongamento dos embriões nos dias $13 \mathrm{e}$ 16.

Tais resultados indicam que a suplementação com $\mathrm{P}_{4}$ deve ser entre os dias cinco e sete após a IA, que embora não promova mudanças nos embriões no estágio de mórula, gera mudanças na expressão gênica, que se manifestarão mais tarde promovendo melhor alongamento do concepto, que irá produzir maior quantidade de IFN- $\tau$, favorecendo o reconhecimento materno. Entretanto, de acordo com os resultados obtidos, em vacas Nelore lactantes, não existe correlação deste fato com a taxa de concepção, pois a mesma foi reduzida quando a suplementação com progesterona foi realizada do dia cinco ao dia 10 após a IATF.

Vacas com baixa $\mathrm{P}_{4}$ apresentam redução do fluxo sanguíneo em torno do CL e os conceptos recuperados através de abate no dia 14 após a IA, foram maiores em novilhas com $\mathrm{P}_{4}$ normal, quando comparados com os recuperados de novilhas com concentrações de $\mathrm{P}_{4}$ consideradas sub-ótimas (FORDE et al., 2011).

Beltman et al. (2009), implantaram dispositivos intravaginais de $\mathrm{P}_{4}$ em um grupo de vacas dos três aos 6,5 dias e em outro grupo dos 4,5 aos oito dias, os pesquisadores observaram que a taxa de sobrevivência embrionária, bem como o peso e o comprimento dos conceptos não foram afetados pelos tratamentos, quando avaliados aos 25 dias após a IA, momento em que os animais foram abatidos.

No intuito de manipular a função luteínica, aumentando assim a concentração sérica de progesterona, Machado et al. (2008), aplicaram 300 UI de Gonadotrofina coriônica equina cinco dias após a IATF em vacas Nelore e não foi observado aumento na taxas de concepção, sugerindo que a elevação nas concentrações circulantes de progesterona não interferiram nos resultados.

Observa-se que em diversos estudos que a suplementação com $\mathrm{P}_{4}$ após a IATF quando realizada mais precocemente 
eleva a taxa de concepção em vacas, contradizendo aos resultados encontrados no presente estudo. Acredita-se que essa divergência de resultados pode ser pelo modo de ação do MGA $^{\circledR}$ Premix, podendo este promover um ambiente uterino inadequado, talvez por variações de $\mathrm{pH}$ uterino, ou algo que possa inviabilizar o bom desenvolvimento e crescimento embrionário, uma vez que o fornecimento deste progestágeno precocemente, na primeira semana após IATF, reduziu as taxas de concepção em vacas Nelore lactantes.

Conclui-se que a suplementação com MGA $^{\circledR} \quad$ Premix, nas condições empregadas neste experimento, em vacas Nelore pluríparas lactantes do $13^{\circ}$ ao $18^{\circ}$ dia após a IATF não melhorou a taxa de concepção e a suplementação do $5^{\circ}$ ao $10^{\circ}$ dia após a IATF reduziu a taxa de concepção de vacas Nelore pluríparas lactantes aos 45 dias após a IATF.

\section{REFERÊNCIAS}

BAZER, F.W.; BURGHARDT, R.C.; JOHNSON, G.A.; SPENCER, T.E.; WU, G. Interferons and progesterone for establishment and maintenance of pregnancy: interactions among novel cell signaling pathways. Reproductive Biology, v.8, n.3, p.179-211, 2008.

BELTMAN, M.E. Effect of progesterone supplementation in the first week postconception on embryo survival in beef heifers.

Theriogenology, v.71, p.1173-1179, 2009.

CARTER, F.; FORDE, N.; DUFFT, P.; WADE, M.; FAIR, T.; CROWE, M.A.; EVANS, A.C.O.; KENNY, D.A.; ROCHE, J.F.; LONERGAN, P. Effect of increasing progesterone concentration from Day 3 of pregnancy on subsequent embryo survival and development in beef heifers.

Reproduction, Fertility and

Development, v.20, n.3, p.368-375, 2008.

CARTER, F.; RINGS, F.; MAMO, S.; HOLKER, M.; KUZMANY, A.; BESENFELDER, U.; HAVLICEK, V.; MEHTA, J.P.; TESFAYE, D.; SCHELLANDER, K.; LONERGAN, P. Effect of Elevated Circulating Progesterone Concentration on Bovine BlastocystDevelopment and Global Transcriptome Following Endoscopic Transfer of In VitroProduced Embryos to the Bovine Oviduct. Biology of Reproduction, v.83, p.707-719, 2010.

FERGUSON, N.; GALLIGAN, D.T.; THOMSEN, N. Principal descriptors of body condition score in Holstein cows.

Journal of Dairy Science, v.77, p.2695-2703, 1994.

FORDE, N.; CARTER, F.; FAIR, T.; CROWE, M.A.; EVANS, A.C.O.; SPENCER, T.E.; BAZER, F.W.; McBRID, R.; BOLAND, M.P.; O'GAORA, P.; LONERGAN, P.; ROCHE, J.F. Progesterone-regulated changes in endometrial gene expression contribute to advanced conceptus development in cattle. Biology of Reproduction, v.81, p.784-794, 2009.

FORDE, N.; BELTMAN, M.E.; DUFFY, G.B.; DUFFY, P.; MEHTA, J.P.; Ó'GAORA, P.; BAZER, F.W.; ROCHE, J.F.; LONERGAN, P.; CROWE, M.A. Changes in the endometrial transcriptome during the bovine estrous cycle: Effect of low circulating progesterone and consequences for conceptus elongation. Biology of Reproduction, v.84, p.266278, 2011. 
Rev. Bras. Saúde Prod. Anim., Salvador, v.15, n.2, p.361-368 abr./jun., 2014 http://www.rbspa.ufba.br ISSN 15199940

HAFEZ, E.S.E; HAFEZ, B. Ciclos reprodutivos. In HAFEZ, E.S.E; HAFEZ, B. (Eds.). Reprodução Animal. 7.ed. Barueri: Manole, 2004. p.55-68.

LARSON, S.F.; BUTLER, W.R.; CURRIE, W.B. Pregnancy rates in lactating dairy cattle following supplementation of progesterone after artificial insemination. Animal

Reproduction Science, v.102. p.172179, 2007.

MACHADO, R.; BERGAMASCHI, M.A.C.M.; BARBOSA, R.T.; MADUREIRA,E.H.; ALENCAR, M.M.; BINELLI, M. Taxas de serviço, concepção e prenhez de vacas nelore tratadas com gonadotrofina coriônica humana e $17 \beta$-estradiol após a inseminação artificial em tempo fixo.Brazilian Journal Veterinary Research Animal Science, v.45. n.3. p.221-230, 2008.

MANN, G.E; LAMMING, G.E. The influence of progesterone during early pregnancy in cattle. Reproduction in Domestic Animals, v.34 p.269-274, 1999.

MANN, G.E; LAMMING, G.E. Relationship between maternal endocrine environment, early embryo development and inhibition of the luteolytic mechanism in cows.

Reproduction, v.121, p.175-180, 2001.

MANN, G.E.; FRAY, M.D.; LAMMING, G.E. Effects of time of progesterone supplementation on embryo development and interferon-tau production in the cow. The Veterinary Journal, v.171, p.500-503, 2006.
NEVES, J.P.; DE OLIVEIRA, J.F.C.; FREITAS, V.J.F.; SIMPLÍCIO, A.A.; TEIXEIRA, D.Í.A.; ALMEIDA, J.L.

Diagnóstico de prenhez em ruminantes. In: GONÇALVES, P.B.D.; FIGUEIREDO, J.R. de; FREITAS, V.J.F. Biotécnicas Aplicadas a Reprodução Animal. 2.ed. São Paulo: ROCA, 2008.

PALHANO, H.B. Fisiologia da Reprodução. In Reprodução em Bovinos. 2.ed. Rio de Janeiro: L. F., 2008. p.33-67.

SÁ FILHO, O.G.; VALARELLI, R.L.; PERES, R.F.G.; HOE, F.G.H.;

MENEGHETTI, M.; VASCONCELOS, J.L.M. Avaliação do uso do acetato de melengestrol (MGA ${ }^{\circledR}$ Premix) em vacas de corte. A Hora Veterinária, v.27, n.158, 2007.

STATISTICAL ANALYSIS SYSTEM. User's guide Version 8. Cary: SAS Institute, 2000. 295p.

SHAMS-ESFANDABADI, N.; SHIRAZI, A. Evaluation of the effect of muscular injection of progesterone on Days 2-5 following insemination on pregnancy rate indairy cows. Pakistan Journal of Biological Sciences, v.10. p.152-155, 2007.

Data de recebimento: 24/07/2013

Data de aprovação: 06/06/2014 